\title{
Effect of High Pressure Processing on Color and Textural Properties of Eggs
}

\author{
Ajaypal $\operatorname{Singh}^{1} \&$ Hosahalli Ramaswamy ${ }^{1}$ \\ ${ }^{1}$ Department of Food Science and Agricultural Chemistry, McGill University, Montreal, Quebec, Canada \\ Correspondence: Hosahalli Ramaswamy, Department of Food Science and Agricultural Chemistry, 21111 \\ Lakeshore Road, MS 01-34, McGill University, Montreal, Quebec, Canada. Tel: 1-514-398-7919. E-mail: \\ hosahalli.ramaswamy@mcgill.ca
}

Received: February 20, 2013 Accepted: June 17, 2013 Online Published: June 19, 2013

doi:10.5539/jfr.v2n4p11

URL: http://dx.doi.org/10.5539/jfr.v2n4p11

\begin{abstract}
Effect of high pressure processing (HPP) on physicochemical characteristics like color and texture of whole liquid egg (WLE), egg white (EW) and egg yolk (EY) were evaluated. A full factorial design involving several pressure levels (600-900 MPa) and treatment time (0-15 min) was employed for this study and the high pressure treatment were given in a temperature and pressure controlled pilot scale HP unit. HPP caused significant changes in various physic-chemical properties in various egg components. Use of pressure levels $\geq 600 \mathrm{MPa}$ resulted in formation of solid gels for all components of eggs. Pressure induced gels were soft and highly elastic. Hardness and cohesiveness of all egg components were found to increase $(p<0.05)$ with increase in treatment intensity, and increase in EY was higher than in other egg components. The springiness of WLE increased with pressure and treatment time and were higher than in EW and EY. Color changes as indicated by the total color difference $(\Delta \mathrm{E})$ showed a significant $(p<0.05)$ increase with an increase in pressure level and treatment time.
\end{abstract}

Keywords: color, texture, high pressure, rheology, egg white, egg yolk, liquid egg

\section{Introduction}

Heat treatments can cause changes in covalent bonds which can increase the formation of off-flavors and quality degradation (Ngarize et al., 2005). Consumer trends in today's food market are preferably inclined more towards minimally processed, fresh like and additive free foods. Many novel food processing technologies have been investigated as a supplementary process or as alternative methods to conventional food processing techniques to promote these concepts. Novel methods include ohmic, radio frequency and microwave heating, ultrasound, high pulsed electric filed or high pressure processing (HPP) applications. HPP has been demonstrated to be an alternative method to satisfy microbiological stability and to retain fresh like characteristics of foods because HPP affected only non-covalent bonds, causing unfolding of protein chains leading to formation of intermolecular bonds between protein molecules while leaving little effect on chemical constituents associated with desirable food qualities such as flavor, color and nutritional content (Hayashi et al., 1989). These intermolecular bonds cause the stabilization of secondary, tertiary and quaternary structure of proteins. HPP treatment has been shown to result in product stabilization and microbial destruction without affecting their sensory qualities (Basak \& Ramaswamy, 1998).

Egg can supply all essential amino acids for humans, and provide several vitamins and minerals, including vitamin $\mathrm{A}$, riboflavin, folic acid, vitamin $\mathrm{B}_{6}$, vitamin $\mathrm{B}_{12}$, choline, iron, calcium, phosphorus and potassium. The egg is a low acid food (higher $\mathrm{pH}$ ) which necessitates preservation by some means to increase the shelf life. Bridgeman (1914) found that egg white gets fully coagulated to form gels, when subjected to pressure level of $600 \mathrm{MPa}$ or more. Texture is considered one of the most important sensory attributes in determining the overall quality, which often undergoes considerable alteration during the thermal pasteurization. HPP at pressures ranging from 400-600 $\mathrm{MPa}$ can cause enough changes in the viscosity of egg components so that it can become gel with improved quality characteristics than the heat induced gels. Pressure induced gels have been reported to be softer and more elastic without any cooked taste and flavour and there was no destruction of vitamins and formation of lysinoalanine (Hayashi et al., 1989). Ovalbumin represents major protein in egg white, and it plays a major role in determining egg white behavior on application of high pressure. HPP can result in structural modification of egg white which can be correlated to enhancement of functional properties (Messens et al., 
1997). This modification influences the SH groups present in ovalbumin and plays a critical function in the formation of protein aggregates and in the stabilization of a gel structure upon heat treatment, which most likely transpires through disulfide exchange mechanism (Mine, 1997). There are number of studies suggesting potential applications and limitations of high-pressure technology for egg gels (Okamato et al., 1990; Rajan et al., 2006; Juliano et al., 2012). Physico-chemical characteristics of egg play an imperative role in behavior of egg proteins during their processing, storage and maintaining sensory attributes, which are not studied in great detail. Hence, the objective of this study was to evaluate effect of high pressure processing on physico-chemical properties of egg components as it changes from highly viscous liquid phase to hard gels (egg patty) with increase in intensity of the high pressure level used.

\section{Materials and methods}

\subsection{Sample Preparation}

Large sized fresh eggs were bought from local grocery store. They were washed and sorted to remove any dirty or leaker eggs. Egg white was separated from egg yolk (EY) by breaking the egg on the tip and allowing the egg white (EW) to flow out leaving the intact egg yolk inside. For preparing whole liquid egg (WLE), eggs were broken and mixed. Test samples were poured into low density 2 oz. polyethylene bags (Whirl Pak ${ }^{(\mathrm{R})}$, USA) and sealed using heat sealer (QUIK SEAL type 210B-1, National instrument co Inc., Baltimore, Maryland). The samples were then stored at $4{ }^{\circ} \mathrm{C}$, removed and equilibrated to the test conditions $\left(20^{\circ} \mathrm{C}\right)$ just prior to pressure treatment as detailed in the next section.

\subsection{High Pressure Treatments}

Samples were then transferred to a $5 \mathrm{~L}$ cylindrical pressure treatment chamber (ACIP 6500/5/12VB; ACB Pressure Systems, Nantes, France). Pure water was used as pressurizing medium in the HP unit. Egg samples were subjected to pressure treatments as shown in Table 1. Pressurization and depressurization rate of $4.4 \mathrm{MPa} / \mathrm{s}$ and $26 \mathrm{MPa} / \mathrm{s}$ respectively, were used during high pressure treatments. Variations in pressure come up and pressure release times were not considered in actual processing time. High pressure level $(>500 \mathrm{MPa})$ were used to form egg patty with better functional properties as it doesn't involve application of any external heat. All the experiments were carried out in duplicate. Pressure treated samples were immediately followed by texture and color measurements. All experiments were carried out at room temperature.

Table 1. Full factorial design combining pressure level and treatment time used

\begin{tabular}{lcccc}
\hline Pressure Level (MPa) & \multicolumn{4}{c}{ Treatment Time (minutes) } \\
\hline 600 & 0 & 5 & 10 & 15 \\
700 & 0 & 5 & 10 & 15 \\
800 & 0 & 5 & 10 & 15 \\
900 & 0 & 5 & 10 & 15 \\
\hline
\end{tabular}

\subsection{Color}

The surface color of treated egg samples was evaluated in L, a, and b units using a tristimulus Minolta CM-508d spectrophotometer (Minolta Co, Japan). The instrument was warmed up for $10 \mathrm{~min}$ before the actual measurements and calibration was performed using a white standard plate. Five measurements were made individually for each sample, and the average value was reported. The color value was determined in a three-dimensional color space, L (luminosity), a (green - to red +), and b (blue- to yellow +) values of the egg samples. In addition, the total color difference, $\Delta \mathrm{E}$ (Equation 1), Chroma (Equation 2) and Hue angle (Equation 3 ) computed from the $\mathrm{L}$, $\mathrm{a}$, and $\mathrm{b}$ values as shown below. Raw egg components were used as the reference for measuring $\Delta \mathrm{E}$, where the subscript "o" refers to the color reading of raw egg component:

$$
\begin{gathered}
\Delta E=\sqrt{\left(L_{0} *-\mathrm{L}^{*}\right)^{2}+\left(a_{0} *-\mathrm{a}^{*}\right)^{2}+\left(b_{0} *-\mathrm{b}^{*}\right)^{2}} \\
\text { Chroma }=\sqrt{ }\left(a *^{2}+b *^{2}\right) \\
\text { Hue angle }=\tan ^{-1}\left(\frac{b^{*}}{a^{*}}\right)
\end{gathered}
$$




\subsection{Texture Profile}

TA.XT plus texture meter with $2 \mathrm{~kg}$ load cell (Texture technologies corp., Scarsdale, NY, USA) was used to evaluate texture profile analysis (TPA) (Figure 1) for the following measurements:

1) Hardness (maximum force required to compress the sample)

2) Adhesiveness (work necessary to pull the compression anvil away from the sample),

3) Springiness (the height that the food recovers during the time that elapses between the end of the first bite and the start of the second bite), and

4) Cohesiveness (the ratio of the positive force area during the second compression portion to that during the first compression (Area 2/Area l)

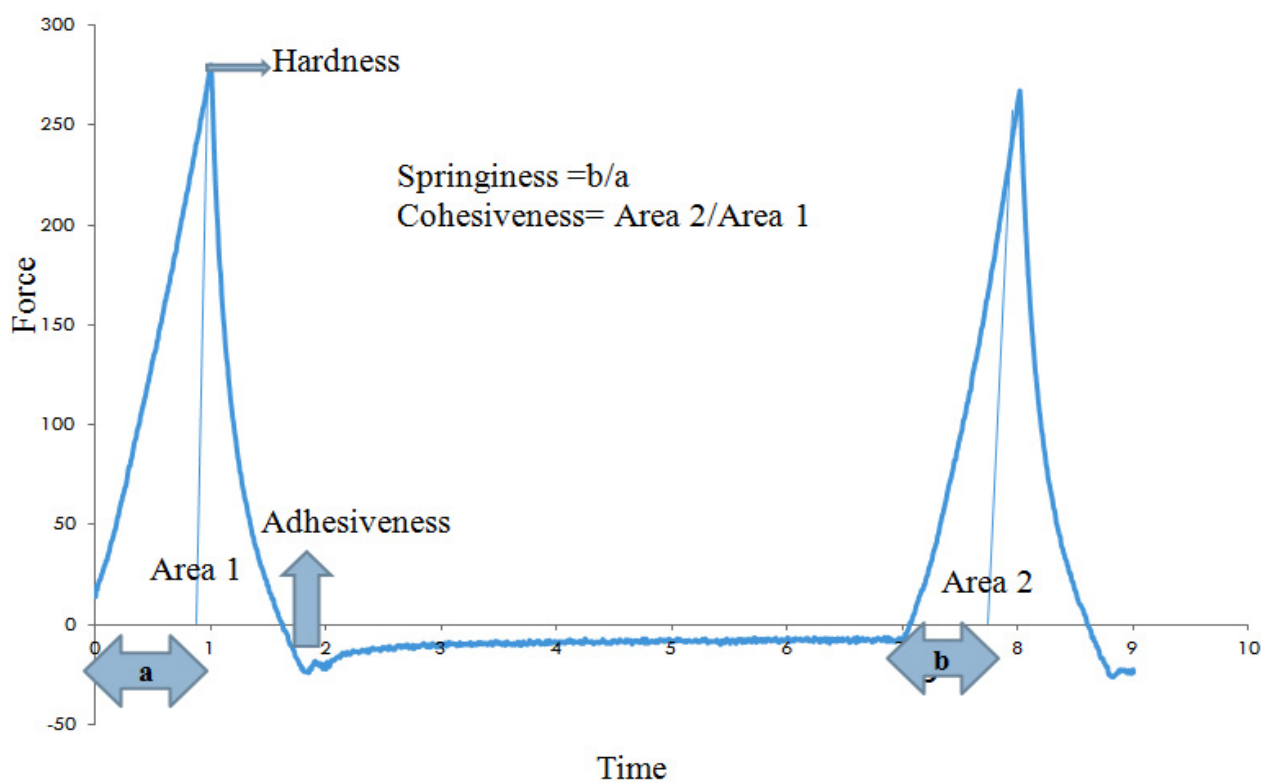

Figure 1. Typical texture profile analysis showing measurement of various parameters

The probe employed in this study was TA- 25 probe (2"diameter cylinder, aluminum, and $20 \mathrm{~mm}$ tall). All experiments were carried out at room temperature $\left(20^{\circ} \mathrm{C}\right)$. In this study, samples were compressed up to $25 \%$ of their original height to calculate TPA. Pre-test, test and post test speed of 1.0, 1.5 and $1.5 \mathrm{~m} / \mathrm{s}$ respectively were used for this test. The instrument automatically recorded the force-displacement or force-time curve and converted them to texture profile analysis. Five to six replicates were conducted for each set of experiment. The compression device was larger than the sample size for TPA, so it confers that forces registered in TPA are largely due to uni-axial compression forces (Bourne, 1982). Part of this work has been presented in Annual meeting of Institute of food technologists, 2010.

\subsection{Statistical Analysis}

A full scale factorial design was used employing 4 levels of pressure (600-900 MPa) and holding time (0-15min) as explained in Table 1. ANOVA analysis was performed on the data using two ways ANOVA with help of Minitab 16 Statistical Software (Minitab Inc, State College, Pa, USA). ANOVA analysis was done and significance level was reported with $95 \%$ level of confidence. It was performed to evaluate effect of treatment factors (time and pressure) and their combination on the color and textural parameters.

\section{Results and Discussions}

\subsection{HP Effects on Color}

\subsubsection{L, a and b Values}

High pressure processing caused number of changes in the color values of egg white (EW), egg yolk (EY) and whole liquid egg (WLE) respectively (Table 2). For all egg components, there were significant $(p<0.05)$ changes caused in their color parameters with variation of the process variables. 
For egg white (EW), it was found that $\mathrm{L}^{*}$ value increased linearly at all pressure-time combinations indicating increase in brightness of sample with increasing pressure treatment intensity. ANOVA analysis showed that both treatment factors (pressure level and treatment time) and their interaction effect were highly significant $(p<0.05)$ in terms of affecting $\mathrm{L}^{*}$ value. In similar way, $\mathrm{a}^{*}$ value followed the identical trend as $\mathrm{L}^{*}$ while the increase in $\mathrm{a}^{*}$ value (indicating the redness of the sample) was minuscule in comparison to $\mathrm{L}^{*}$ value. ANOVA analysis suggested that treatment factors and their interaction affected $a^{*}$ value in a significant way. Similarly, there was small increase in $\mathrm{b}^{*}$ value from 1.91 to 2.21, though it was indicated by ANOVA analysis that this change was significant $(p<0.05)$. ANOVA analysis shows that in all egg components, $\mathrm{R}^{2}$ was found to be $>0.95$ indicating high significance of the two-way ANOVA model used.

Egg Yolk being high in xanthophylls (yellow color) showed altogether different color behavior than that of egg white. Egg yolk showed increase in viscosity and its color changed from pale yellow to orange yellow as per visual appearance. $\mathrm{L}^{*}$ value remained constant showing a minute increase from 57.4 to 58.5 only where as a* value was found to be decreasing from 9.51 to 2.11 indicating diminution in redness of sample but on the other hand, $\mathrm{b}^{*}$ value increased significantly $(p<0.05)$ from 56.5 to 76.5 showing great deal of increase in yellow color of the egg yolk.

Table 2. Hunter color values of the egg white subjected to pressure level and treatment time

\begin{tabular}{|c|c|c|c|c|c|}
\hline Egg White & Time(min) & $\mathbf{0}$ & 5 & 10 & 15 \\
\hline & sure (MPa). & & & & \\
\hline \multirow[t]{4}{*}{$L^{*}$ value } & 600 & $58.0 \pm 0.71$ & $63.5 \pm 3.54$ & $66.2 \pm 4.24$ & $80.0 \pm 1.14$ \\
\hline & 700 & $81.0 \pm 1.41$ & $86.0 \pm 0.00$ & $85.5 \pm 0.70$ & $91.5 \pm 0.70$ \\
\hline & 800 & $86.0 \pm 3.53$ & $89.2 \pm 4.24$ & $91.5 \pm 2.12$ & $96.0 \pm 1.41$ \\
\hline & 900 & $88.0 \pm 2.82$ & $91.5 \pm 3.50$ & $94.5 \pm 1.41$ & $100.5 \pm 0.70$ \\
\hline \multirow{4}{*}{$a^{*}$ value } & 600 & $1.2 \pm 0.01$ & $2.0 \pm 0.02$ & $2.2 \pm 0.04$ & $2.3 \pm 0.01$ \\
\hline & 700 & $2.8 \pm 0.07$ & $2.9 \pm 0.01$ & $3.1 \pm 0.03$ & $3.1 \pm 0.01$ \\
\hline & 800 & $1.9 \pm 0.65$ & $2.1 \pm 0.02$ & $2.0 \pm 0.01$ & $2.3 \pm 0.07$ \\
\hline & 900 & $1.9 \pm 0.02$ & $2.1 \pm 0.02$ & $2.0 \pm 0.01$ & $2.2 \pm 0.07$ \\
\hline \multirow[t]{4}{*}{$b^{*}$ value } & 600 & $1.9 \pm 0.92$ & $1.6 \pm 0.01$ & $1.8 \pm 0.00$ & $2.2 \pm 0.07$ \\
\hline & 700 & $1.5 \pm 0.14$ & $1.2 \pm 0.01$ & $1.1 \pm 0.01$ & $1.2 \pm 0.07$ \\
\hline & 800 & $1.3 \pm 0.07$ & $1.1 \pm 0.01$ & $0.9 \pm 0.01$ & $0.8 \pm 0.02$ \\
\hline & 900 & $0.1 \pm 0.01$ & $1.1 \pm 0.02$ & $1.6 \pm 0.02$ & $2.2 \pm 0.00$ \\
\hline \multicolumn{6}{|l|}{ Egg Yolk } \\
\hline \multirow[t]{4}{*}{$L^{*}$ value } & 600 & $57.4 \pm 0.84$ & $56.8 \pm 0.28$ & $53.8 \pm 0.21$ & $61.1 \pm 0.14$ \\
\hline & 700 & $57.0 \pm 1.34$ & $55.7 \pm 0.49$ & $51.7 \pm 0.35$ & $44.8 \pm 0.07$ \\
\hline & 800 & $55.3 \pm 0.98$ & $50.6 \pm 0.84$ & $50.6 \pm 0.56$ & $51.2 \pm 0.07$ \\
\hline & 900 & $57.2 \pm 1.41$ & $53.1 \pm 0.21$ & $55.1 \pm 0.28$ & $58.5 \pm 0.28$ \\
\hline \multirow[t]{4}{*}{$a^{*}$ value } & 600 & $9.5 \pm 0.01$ & $8.5 \pm 0.05$ & $8.4 \pm 0.01$ & $61.5 \pm 0.07$ \\
\hline & 700 & $8.6 \pm 0.04$ & $5.8 \pm 0.06$ & $5.4 \pm 0.05$ & $4.1 \pm 0.07$ \\
\hline & 800 & $4.1 \pm 0.07$ & $2.9 \pm 3.07$ & $2.6 \pm 0.28$ & $1.8 \pm 0.07$ \\
\hline & 900 & $3.9 \pm 0.07$ & $2.8 \pm 0.09$ & $2.4 \pm 0.06$ & $2.1 \pm 0.01$ \\
\hline \multirow[t]{4}{*}{$b^{*}$ value } & 600 & $44.2 \pm 15.21$ & $56.1 \pm 1.20$ & $58.1 \pm 0.14$ & $58.1 \pm 0.14$ \\
\hline & 700 & $61.1 \pm 0.14$ & $62.5 \pm 0.70$ & $62.2 \pm 1.06$ & $63.4 \pm 1.27$ \\
\hline & 800 & $64.0 \pm 0.35$ & $66.5 \pm 3.53$ & $70.4 \pm 0.28$ & $70.6 \pm 0.28$ \\
\hline & 900 & $69.3 \pm 1.83$ & $70.5 \pm 2.12$ & $72.5 \pm 2.12$ & $75.5 \pm 0.70$ \\
\hline
\end{tabular}




\begin{tabular}{cccccc}
\hline L* value & $\mathbf{6 0 0}$ & $47.9 \pm 0.01$ & $48.6 \pm 0.49$ & $53.4 \pm 0.56$ & $58.6 \pm 0.84$ \\
& $\mathbf{7 0 0}$ & $53.6 \pm 0.56$ & $53.5 \pm 0.77$ & $55.1 \pm 0.28$ & $61.8 \pm 0.14$ \\
& $\mathbf{8 0 0}$ & $57.1 \pm 0.21$ & $61.3 \pm 0.49$ & $65.5 \pm 0.70$ & $65.5 \pm 0.21$ \\
& $\mathbf{9 0 0}$ & $59.1 \pm 0.21$ & $65.1 \pm 0.21$ & $67.9 \pm 0.14$ & $68.3 \pm 0.14$ \\
\hline a*value & $\mathbf{6 0 0}$ & $15.4 \pm 0.07$ & $16.1 \pm 0.21$ & $19.1 \pm 0.14$ & $25.1 \pm 0.21$ \\
& $\mathbf{7 0 0}$ & $17.1 \pm 0.21$ & $18.1 \pm 0.14$ & $19.7 \pm 0.28$ & $23.5 \pm 0.70$ \\
& $\mathbf{8 0 0}$ & $19.0 \pm 0.21$ & $18.1 \pm 0.21$ & $21.2 \pm 0.28$ & $24.8 \pm 0.70$ \\
& $\mathbf{9 0 0}$ & $19.7 \pm 0.42$ & $20.6 \pm 0.14$ & $21.5 \pm 0.21$ & $27.1 \pm 0.28$ \\
\hline b* value & $\mathbf{6 0 0}$ & $31.5 \pm 0.07$ & $32.0 \pm 0.07$ & $34.0 \pm 0.28$ & $37.5 \pm 0.70$ \\
& $\mathbf{7 0 0}$ & $34.3 \pm 0.21$ & $35.1 \pm 0.42$ & $36.1 \pm 0.21$ & $37.0 \pm 0.14$ \\
& $\mathbf{8 0 0}$ & $35.1 \pm 0.14$ & $37.1 \pm 0.21$ & $39.6 \pm 0.63$ & $41.3 \pm 0.07$ \\
& $\mathbf{9 0 0}$ & $38.1 \pm 0.07$ & $39.6 \pm 0.141$ & $40.7 \pm 0.14$ & $45.4 \pm 0.28$ \\
\hline
\end{tabular}

High pressure level of $900 \mathrm{MPa}$ showed the maximum $\mathrm{L}^{*}$ and $\mathrm{b}^{*}$ values of treated samples. In similar fashion to EW, it was found that $\mathrm{R}^{2}$ values were greater than $0.95 \%$ indicating higher efficacy of ANOVA ( 2 way model) used.

For WLE, $L^{*}$ value increased significantly $(p<0.05)$ from 47.90 to 68.30 showing increase in lightness of sample. In similar way, $\mathrm{a}^{*}$ and $\mathrm{b}^{*}$ value were found to be rising significantly $(p<0.05)$ from 15.45 to 27.1 and 31.55 to 45.4 respectively which indicated that whole egg samples were more attractive with increased lightness and reddish yellow color.

Effect of pressure level, treatment time and their interaction was found to be highly significant. The main possible reason for changes in egg samples could be rearrangement of water molecules after pressure treatment that tend to modify the gel network, exhibiting a more lustrous and transparent appearance than heat-induced gels (Munizaga \& Barbosa, 2004). In other similar studies, it was found that egg gels treated with high pressure keep their original taste without any cooked flavor (Okomato et al., 1989).

Even in case of other protein rich foods, it was found that the HPP can cause many changes in fish muscle in terms of color and texture (Zhu \& Ramaswamy, 2004). There are mainly 3 carotenoids which are responsible for yellow color in the egg products: Lutein, zeaxanthin and cryptoxanthin (Powrie \& Nakai, 1986) and HPP modify these pigments in such a way that modifies the color characteristics of egg gels.

\subsection{2 $\Delta \mathrm{E}$, Hue Angle and Chroma}

$\Delta \mathrm{E}$ is the total color difference which was obtained as the combined differences in $\mathrm{L}^{*}, \mathrm{a}^{*}$, and $\mathrm{b}^{*}$ values and has been comprehensively employed to present the color variance of foods during processing (Azarpazhooh \& Ramaswamy, 2011). $\Delta \mathrm{E}$ was calculated using $\mathrm{L}^{*}, \mathrm{a}^{*}$ and $\mathrm{b}^{*}$ values whereas raw egg components acted as reference. $\Delta \mathrm{E}$ was quite significantly $(p<0.05)$ affected by all process variables and their interaction. Hue angle (H) can be described as the degree to which a stimulus can be described as similar to or different from red, yellow and blue color. A hue angle $>90^{\circ}$ indicates yellowish green color whereas Hue angle $<90^{\circ}$ indicates more orange color. Chroma depicts the strength of color and it is related to degree of saturation.

In $\mathrm{EW}, \Delta \mathrm{E}$ value increased linearly from 600-900 MPa with increase in treatment time rising from 0-15 min (Table 3). $\Delta \mathrm{E}$ value showed an approximate $100 \%$ increase as it elevated from 58 to 104 accompanied by visual change in color of egg white. The EW coagulated with increase in pressure level and treatment time, thereby changing its color from slightly transparent to opaque. The main factor responsible for change in color of egg white could be due to impact of high pressure on texture as structure and pigments of food interact with each other to affect color and translucency/opacity (Oey et al., 2008).

In EW, Hue angle showed opposite trend to that of $\Delta \mathrm{E}$. It was found using ANOVA analysis that treatment factors and their interaction was highly significant $(p<0.05)$ in affecting Hue angle. Increase in pressure level and treatment time range caused decrease in Hue angle but decrease was very minimal in comparison to increase in $\Delta \mathrm{E}$ values. There was small yet significant $(p<0.05)$ increase in Chroma value with increase in processing treatment level. High pressure affects the textural properties which in turn affects the nature and extent of scattered light and distribution of surface reflectance leading to color change (MacDougall, 2002). 
Table 3. Effect of HP treatments on $\Delta \mathrm{E}$, Hue angle and Chroma values of egg components

\begin{tabular}{|c|c|c|c|c|c|}
\hline Egg White & Time(min) & $\mathbf{0}$ & 5 & 10 & 15 \\
\hline & Pressure (MPa) & & & & \\
\hline \multirow[t]{4}{*}{ Delta $E(\Delta E)$} & 600 & $57.5 \pm 0.71$ & $63.5 \pm 3.34$ & $68.1 \pm 3.86$ & $83.4 \pm 1.72$ \\
\hline & 700 & $89.6 \pm 2.37$ & $93.9 \pm 0.13$ & $98.6 \pm 1.08$ & $101.7 \pm 0.61$ \\
\hline & 800 & $84.3 \pm 1.10$ & $89.0 \pm 4.42$ & $91.0 \pm 2.17$ & $98.5 \pm 0.77$ \\
\hline & 900 & $88.6 \pm 2.65$ & $91.8 \pm 3.70$ & $94.1 \pm 1.51$ & $103.7 \pm 0.03$ \\
\hline \multirow[t]{4}{*}{ Hue angle } & 600 & $57.8 \pm 0.41$ & $38.8 \pm 0.05$ & $39.1 \pm 0.42$ & $44.9 \pm 0.72$ \\
\hline & 700 & $29.3 \pm 1.49$ & $22.2 \pm 0.33$ & $19.5 \pm 0.02$ & $21.8 \pm 1.21$ \\
\hline & 800 & $43.9 \pm 1.42$ & $28.2 \pm 0.05$ & $26.0 \pm 0.40$ & $20.0 \pm 1.01$ \\
\hline & 900 & $27.5 \pm 0.07$ & $27.4 \pm 0.69$ & $38.6 \pm 0.27$ & $44.5 \pm 0.62$ \\
\hline \multirow[t]{4}{*}{ Chroma } & 600 & $2.2 \pm 0.03$ & $2.6 \pm 0.02$ & $2.9 \pm 0.03$ & $3.2 \pm 0.05$ \\
\hline & 700 & $3.3 \pm 0.13$ & $3.1 \pm 0.07$ & $3.3 \pm 0.03$ & $3.4 \pm 0.01$ \\
\hline & 800 & $2.0 \pm 0.42$ & $2.3 \pm 0.02$ & $2.2 \pm 0.00$ & $2.5 \pm 0.06$ \\
\hline & 900 & $2.1 \pm 0.02$ & $2.3 \pm 0.01$ & $2.6 \pm 0.01$ & $3.2 \pm 0.06$ \\
\hline \multicolumn{6}{|l|}{ Egg Yolk } \\
\hline \multirow[t]{4}{*}{ Delta $E(\Delta E)$} & 600 & $520 \pm 10.17$ & $622 \pm 34.12$ & $673 \pm 28.8$ & $808 \pm 8.00$ \\
\hline & 700 & $831 \pm 41.31$ & $912 \pm 0.44$ & $851 \pm 40.9$ & $990 \pm 9.02$ \\
\hline & 800 & $1007 \pm 43.34$ & $1352 \pm 62.8$ & $1436 \pm 9.10$ & $1428 \pm 11.2$ \\
\hline & 900 & $1275 \pm 50.72$ & $1497.8 \pm 53$ & $1741 \pm 57.0$ & $1871 \pm 0.16$ \\
\hline \multirow[t]{4}{*}{ Hue angle } & 600 & $80.2 \pm 0.22$ & $81.6 \pm 0.14$ & $81.8 \pm 0.07$ & $84.2 \pm 0.07$ \\
\hline & 700 & $82.0 \pm 0.05$ & $84.7 \pm 0.05$ & $85.0 \pm 0.10$ & $86.3 \pm 0.07$ \\
\hline & 800 & $86.3 \pm 0.10$ & $87.6 \pm 0.08$ & $87.9 \pm 0.22$ & $88.5 \pm 0.06$ \\
\hline & 900 & $86.7 \pm 0.02$ & $87.8 \pm 0.05$ & $88.2 \pm 0.03$ & $88.4 \pm 0.01$ \\
\hline \multirow[t]{4}{*}{ Chroma } & 600 & $56.0 \pm 0.21$ & $58.1 \pm 0.69$ & $59.2 \pm 0.56$ & $61.4 \pm 0.13$ \\
\hline & 700 & $62.1 \pm 0.70$ & $63.3 \pm 0.05$ & $62.2 \pm 0.69$ & $64.5 \pm 0.13$ \\
\hline & 800 & $64.6 \pm 0.70$ & $69.7 \pm 0.84$ & $70.7 \pm 0.15$ & $70.5 \pm 0.13$ \\
\hline & 900 & $68.6 \pm 0.71$ & $71.5 \pm 0.71$ & $74.5 \pm 0.70$ & $76.0 \pm 0.03$ \\
\hline \multicolumn{6}{|l|}{ Whole liquid egg } \\
\hline \multirow[t]{4}{*}{ Delta $E(\Delta E)$} & 600 & $190 \pm 2.38$ & $213 \pm 5.61$ & $323.1 \pm 1.93$ & $614 \pm 23.3$ \\
\hline & 700 & $268 \pm 8.06$ & $306 \pm 0.67$ & $374 \pm 13.14$ & $537 \pm 31.5$ \\
\hline & 800 & $339 \pm 9 . .01$ & $347 \pm 10.7$ & $504 \pm 25.52$ & $691 \pm 28.9$ \\
\hline & 900 & $413 \pm 15.41$ & $481 \pm 8.42$ & $544 \pm 11.57$ & $922 \pm 3.90$ \\
\hline \multirow[t]{4}{*}{ Hue angle } & 600 & $63.9 \pm 0.05$ & $63.2 \pm 0.25$ & $60.7 \pm 0.38$ & $56.1 \pm 0.27$ \\
\hline & 700 & $63.5 \pm 0.14$ & $62.7 \pm 0.46$ & $61.4 \pm 0.20$ & $57.6 \pm 0.68$ \\
\hline & 800 & $61.5 \pm 0.17$ & $64.0 \pm 0.13$ & $61.9 \pm 0.06$ & $59.0 \pm 0.76$ \\
\hline & 900 & $62.7 \pm 0.46$ & $62.5 \pm 0.07$ & $62.1 \pm 0.15$ & $59.2 \pm 0.42$ \\
\hline \multirow[t]{4}{*}{ Chroma } & 600 & $35.1 \pm 0.1$ & $35.9 \pm 0.15$ & $39.0 \pm 0.17$ & $45.1 \pm 0.70$ \\
\hline & 700 & $38.4 \pm 0.28$ & $39.5 \pm 0.31$ & $41.2 \pm 0.32$ & $43.8 \pm 0.49$ \\
\hline & 800 & $39.9 \pm 0.22$ & $41.3 \pm 0.28$ & $45.0 \pm 0.69$ & $48.2 \pm 0.30$ \\
\hline & 900 & $42.9 \pm 0.25$ & $44.6 \pm 0.19$ & $46.0 \pm 0.22$ & $52.9 \pm 0.09$ \\
\hline
\end{tabular}

In $\mathrm{EY}, \Delta \mathrm{E}$ was found to be increasing with increase in pressure level and treatment time. ANOVA analysis states that both treatment factors and their interaction had significant $(p<0.05)$ affect on $\Delta \mathrm{E}$ value. There was nominal 
but significant $(p<0.05)$ increase in Hue angle from 80 to 88 with increase in treatment intensity but on the other hand, Chroma values increased significantly from 56 to 76 which was found to be highly significant $(p<0.05)$.

WLE that showed a different pattern from EW and EY due to difference in their composition and their response to HPP. $\Delta \mathrm{E}$ value increased significantly $(p<0.05)$ from 190 to 922 . There was tremendous increase in $\Delta \mathrm{E}$ (approximately 5 fold) which is much higher than that of EW and EY. Small decrease in Hue angle (64 to 59) was observed indicating decrease in yellowish color of the product. On the other hand, Chroma increased from 35 to 53 which was highly significant $(p<0.05)$, but it was lower than EY and higher than that of EW.

From these results, it was observed that HPP can cause significant changes in color of egg components which can be related to changes in textural properties as they change from fully flowing liquid to fully formed gels on application of increasing intensity of pressure treatment.

This similar phenomenon was observed in another study on tomato products, where HP treatment $(400 \mathrm{MPa} / 25$ $\mathrm{C} / 15 \mathrm{~min}$ ) caused increase in $\mathrm{L}^{*}$ value of surface color of puree indicating increase in lightening of puree surface. The possible reason could be the formation of jelly like viscous translucent tomato puree when high pressure processing was used (Verlent et al., 2006). It was found that changes in color appearance would be more expected rather than the changes in pigment concentration (MacDougall, 2002).

\subsection{HP Effects on Texture of Egg Components}

EW showed different behavior than those of EY and WLE due to their high protein content. Application of HPP caused coagulation of egg white and increasing the intensity of pressure level and treatment time caused the gelation of egg white like that of an egg patty. Texture profile analysis of treated samples was done to evaluate Hardness, Adhesiveness, Cohesiveness, Chewiness, Gumminess and Springiness. Egg white turned opaque at $600 \mathrm{MPa}$ and at treatment of $600 \mathrm{MPa} / 15$ min was able to form egg gels which can stand by themselves. Egg yolk was able to form gels at $700 \mathrm{MPa} / 15 \mathrm{~min}$ and WLE was able to form gels at very short time processing treatment of $700 \mathrm{MPa} / 10 \mathrm{~min}$.

\subsubsection{Hardness}

Hardness is mainly known as force required for attaining a given deformation or maximum force which occurs at any time during first compression cycle (Szczesniak, 1963). Hardness was measured to evaluate increasing gelation of egg components. This property was used to depict changes caused in hardness level due to increasing gelation in various egg components. Egg white proteins called ovalbumin, ovotransferrin, and lyzozyme are responsible for gelation (Johnson \& Zabik, 1981).

ANOVA was used to evaluate significance of the results. $p$ value was used for representing significance level. Smaller $p$ value depicts higher significance level. Egg white hardness increased with increasing pressure and time treatment intensity (Figure 2). Increase in hardness value at higher processing pressure and time were steeper indicating that a certain critical minimum pressure and treatment time are required for proper gelation of egg white to form solid egg gel patty. Egg yolk (EY) showed similar pattern to that of EW but EY had 50\% more increase than $\mathrm{EW}$. 


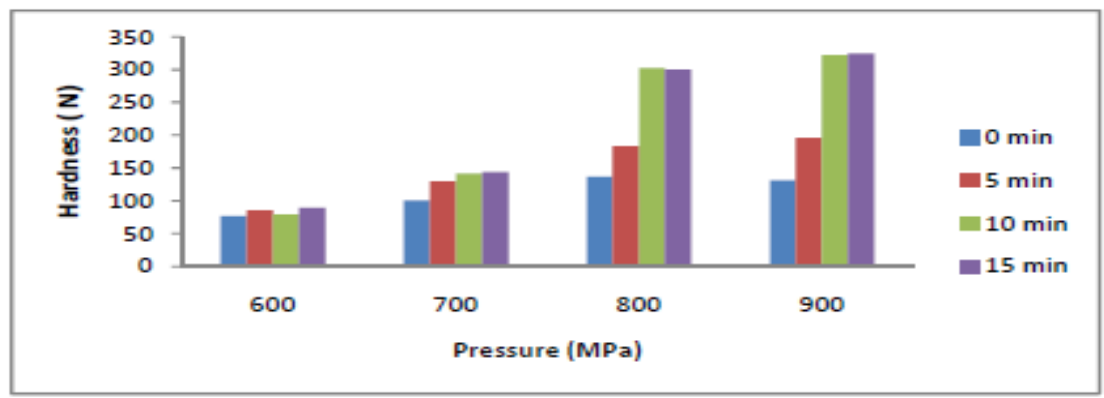

(a)

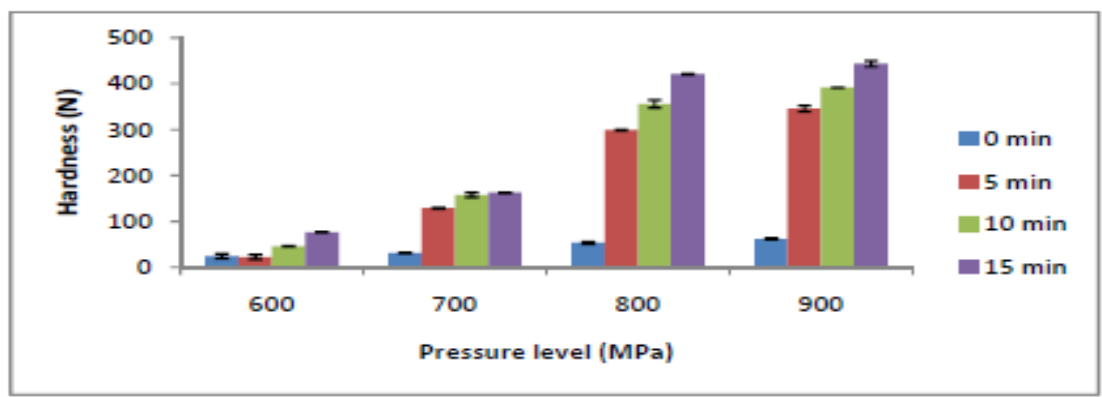

(b)

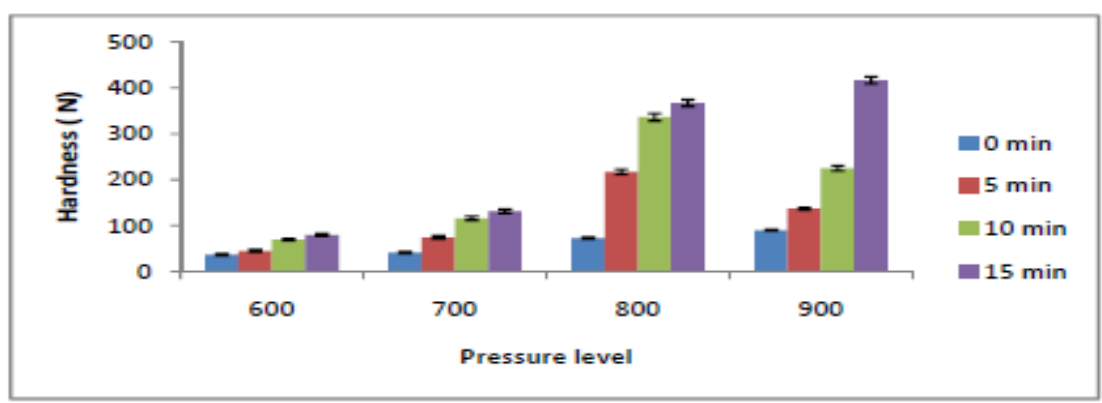

(c)

Figure 2. Effect of High pressure processing and treatment time on hardness of various egg components:

(a) EW, (b) EY, and (c) WLE

Egg white and egg yolk are important functional ingredients which can show gelation upon pressure processing and it can be used in preparation and texture modification of food products (Paraskevopoulos \& Kiosseoglou, 1997). Hardness of WLE also increased with increase in pressure level and treatment time but hardness values were lower than EY and higher than EW.

Tunick et al. (1991) found that higher level of hardness could be due to reduced moisture level. They hypothesized that alteration in protein matrix and water acting as lubricant or plasticizer between proteins is the primary reason for increasing firmness. In another study, it was found that high protein content and the type of protein present in matrix results in compact and dense appearance and concluded that protein content is most closely related with hardness of cheese varieties (Chen et al., 1979). The increase in hardness by high pressure was found due to gelation which is a complex process involving protein denaturation and aggregation (Hermansson, 1982). In this study, ANOVA indicated that both treatment factors and their interaction was highly significant $(p<0.05)$. It was found that hardness of all egg components behaved in same manner (increasing hardness with increasing treatment intensity).

ANOVA analysis for EY and WLE indicated that both treatment factors and their interaction were highly significant $(p<0.05)$. It was found that pressure treated samples gave an impression similar to that of cooked egg gels but gels formed were very adhesive and elastic. In a similar study it was found that high pressure coagulated egg white gels were more adhesive and elastic than thermally treated gels (Hayashi et al., 1989). 
Correspondingly Carlez et al. (1995) reported that high pressure processed gels have softer structure than that of thermal treatments.

\subsubsection{Adhesiveness}

Adhesiveness is more of a surface characteristic and depends on a combined effect of adhesive and cohesive forces, and also an indicator of viscosity and viscoelastic properties as well. Adhesiveness is related to surface properties and is known as the work necessary to overcome the attractive forces between the food and surface of other materials. It is also known as negative peak beneath the base line of texture profile which depicts force required to pull out plunger from the sample (Friedman et al., 1963).

Adhesiveness decreased linearly with increase in pressure level and treatment time for EW (Figure 3). ANOVA analysis showed that both factors affected the adhesiveness in significant $(p<0.05)$ manner but the interaction effect of these two parameters showed a non-significant $(p>0.05)$ role. EY followed a different pattern as adhesiveness increased to its maximum value at pressure level of $800 \mathrm{MPa}$ and then decreased towards end at pressure level of $900 \mathrm{MPa}$. WLE followed an increasing trend, but adhesiveness value of EW was 2 fold to that of the WLE. Egg components followed EY > EW > WLE pattern for adhesiveness, where EY demonstrated maximum hardness. Increasing pressure level from 500-900 MPa affected the adhesion properties of egg components in a very comprehensive manner. The possible reason for highest increase in egg yolk could be the higher amount of fat present in egg yolk matrix, thus increasing adhesiveness. ANOVA results illustrated that all treatment factors and their interaction affected adhesiveness in significant manner $(p<0.05)$.

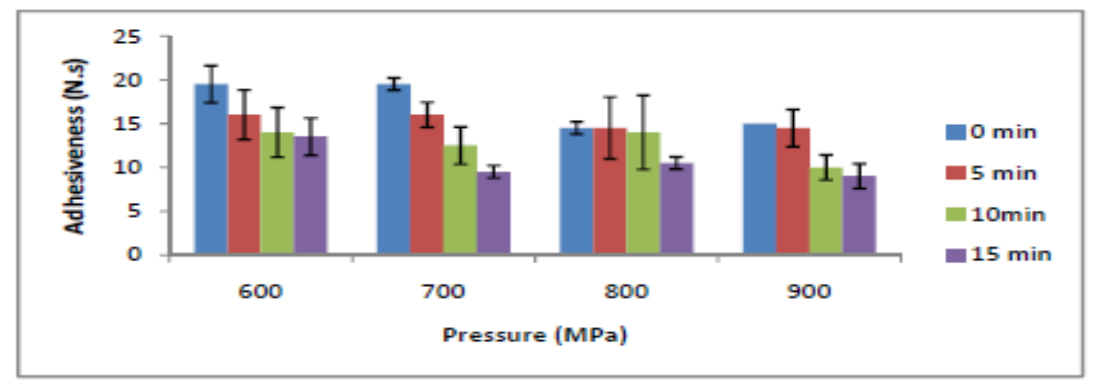

(a)

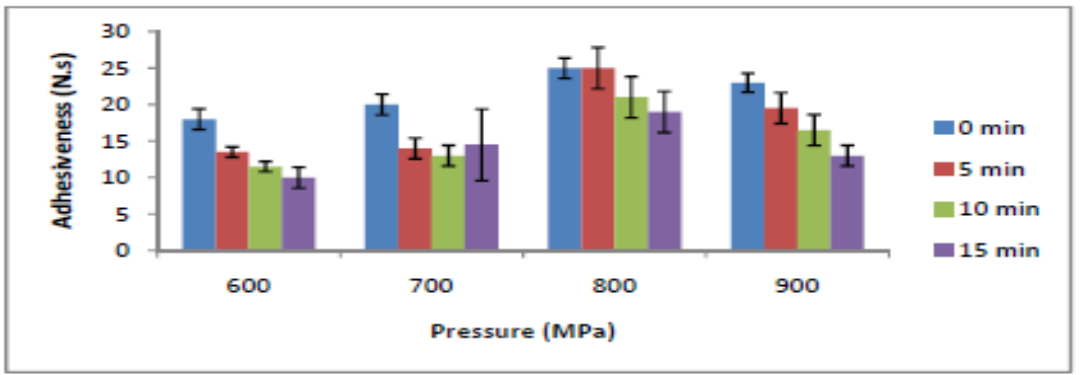

(b)

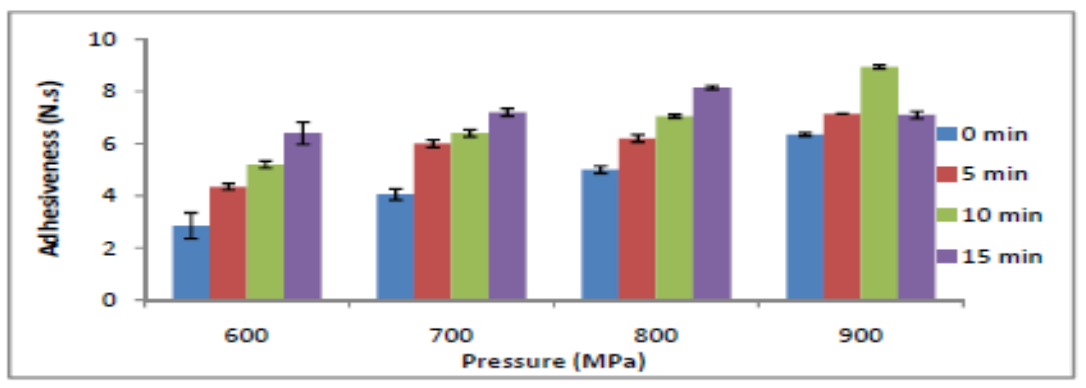

(c)

Figure 3. Effect of High pressure processing and treatment time on adhesiveness of various egg components: (a) EW, (b) EY, and (c) WLE 


\subsubsection{Springiness}

Springiness is the ability of a product to spring back after deformation during first compression. Spring back is measured at down stroke of second compression, so duration time between two compressions is very important. Springiness was earlier known as elasticity. The ability of various egg components to show springiness is very important as they are used as gels and it may also influence texture and acceptability of food such as cakes, biscuits and omelets. High pressure treated EW showed small but significant $(p<0.05)$ change in springiness (Figure 4). ANOVA analysis showed that pressure level was more significant $(p>0.05)$ then treatment time in terms of affecting springiness.

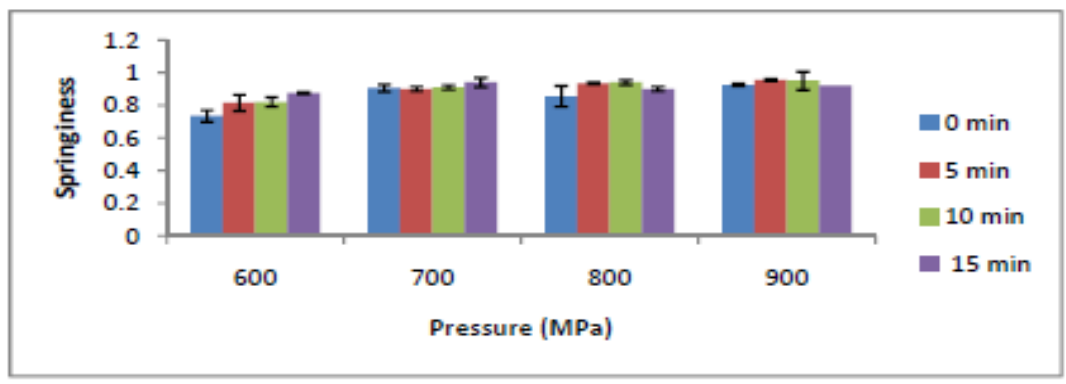

(a)

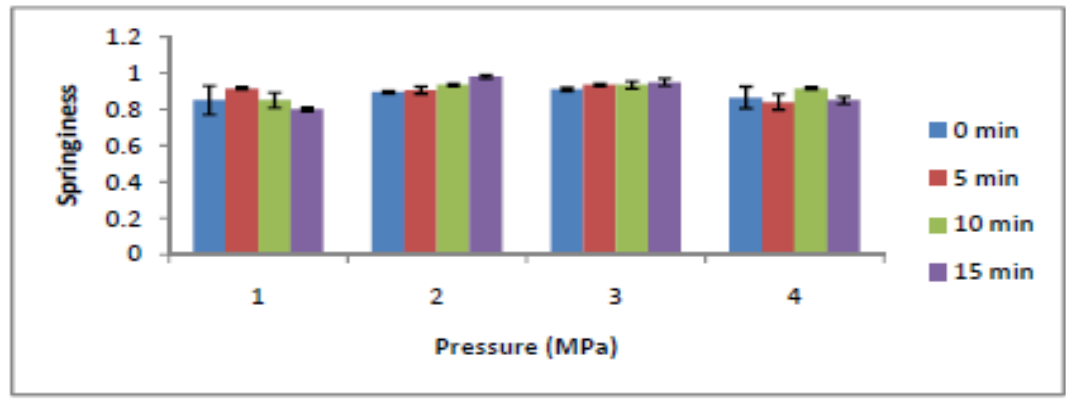

(b)

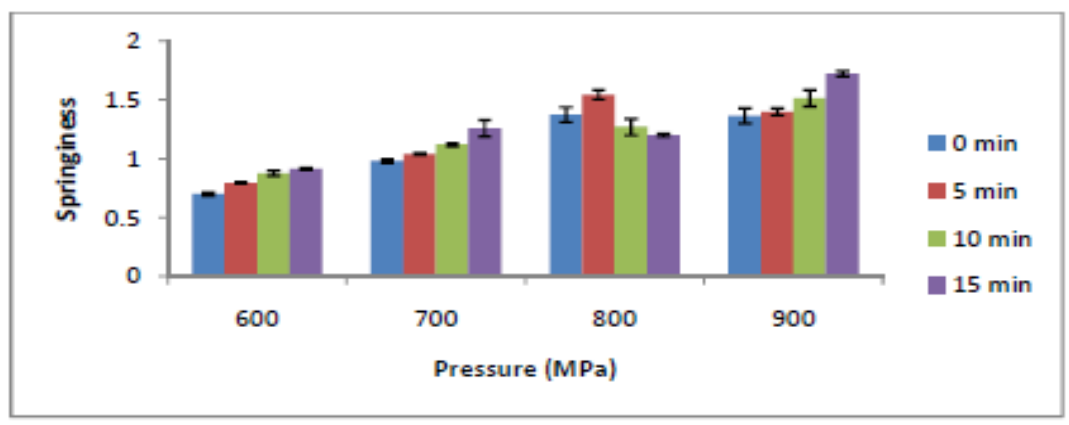

(c)

Figure 4. Effect of High pressure processing and treatment time on springiness of various egg components: (a) EW, (b) EY, and (c) WLE

Even the interaction effect of pressure and time was non-significant. On other hand for EY, springiness showed rather inconsistent pattern as it showed increase in springiness followed by decrease in its value by increasing pressure level and treatment time. ANOVA analysis illustrated that effect of pressure was significant $(p<0.05)$ but treatment time was insignificant factor $(p>0.05)$. For WLE, it was found using the ANOVA analysis that all factors and their interaction effects were highly significant $(p<0.05)$. WLE followed a different trend than that of EW and EY as springiness increased with increasing pressure and treatment time.

\subsubsection{Cohesiveness}

Cohesiveness is defined as ratio of area under second peak and area of first peak in a double mode compression test and it represents the internal bonds making up the body. Cohesiveness was calculated using TPA and it 
differed significantly in HPP treated egg samples. In case of EW, the cohesiveness showed a very small increase with increase in treatment intensity (Figure 5). Even with ANOVA analysis it was found that impact of pressure, time and their interaction on cohesiveness was not significant $(p>0.05)$. EY behaved in different manner in terms of cohesiveness characteristics than that of EW. Increase in pressure level and treatment time both caused increase in cohesiveness value, but increasing pressure level had more significant $(p<0.005)$ effect than treatment time $(p>0.005)$. Interaction effect of pressure level and treatment time was found to be non-significant $(p>0.05)$. Cohesiveness was not found to be showing non linear pattern in WLE, but with increasing treatment intensity, the overall behavior shown was decreasing trend in cohesiveness. ANOVA analysis showed that effect of treatment factors and their interaction on cohesiveness was highly significant ( $p \leq$ 0.05 ) which means that varying pressure level and treatment time played a significant role in affecting cohesiveness. During compression, fracture was not calculated, so this cohesiveness may not be ideal cohesiveness. It is more likely the elastic-plastic nature of the sample which could be affected by combination of cohesiveness and adhesiveness.

In a similar study, Mateos et al. (1996) found that temperature and pressure have a linear effect on cohesiveness $(p \leq 0.01)$ in gels with their highest cohesiveness values occurring at low temperatures and low pressures. Heating could, perhaps, be the factor that caused cohesiveness to be significantly similar. It was found that sol-gel conversion involves protein denaturation followed by aggregation of protein molecules, eventually forming well defined highly cohesive molecular network to form solid phase. The protein can denature partially as high pressure treatment causes denaturation of ovotransferrin, ovalbumin and lyzozyme.

High pressure can cause the denaturation and coagulation to increase the proteolysis similar to that of heat but high pressure treated gels have highly elastic and adhesion properties compared to thermally treated egg. 


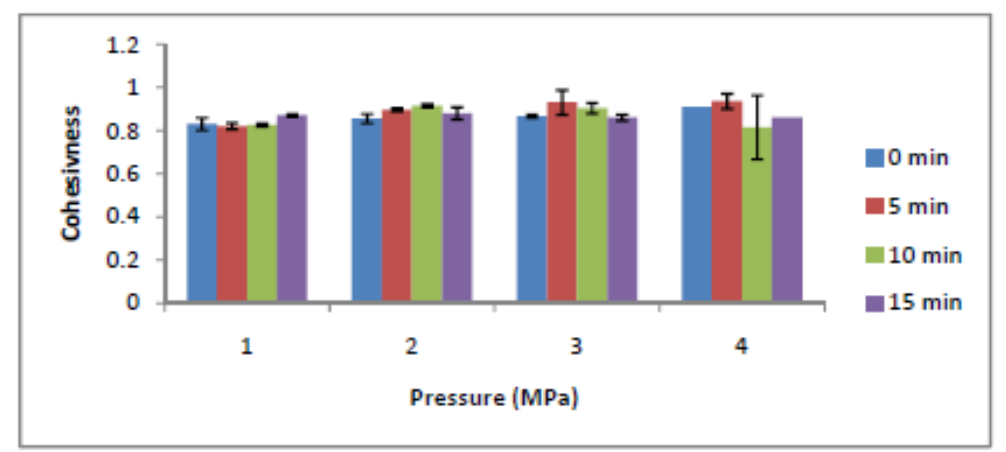

(a)

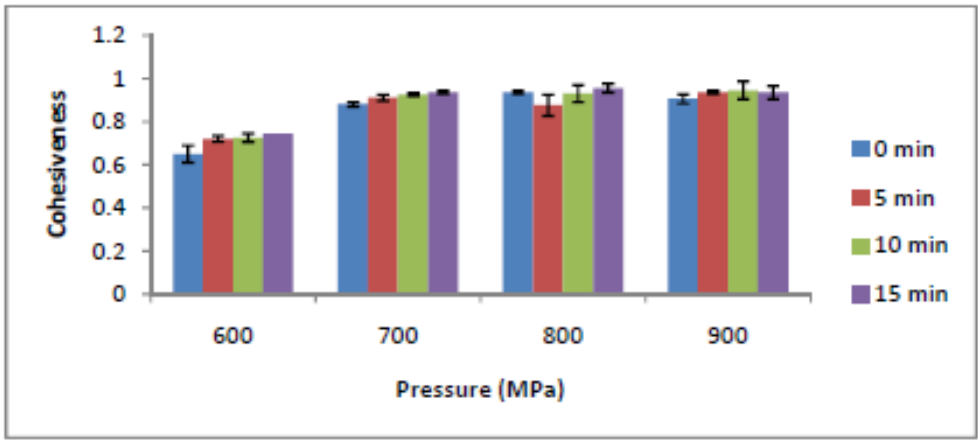

(b)

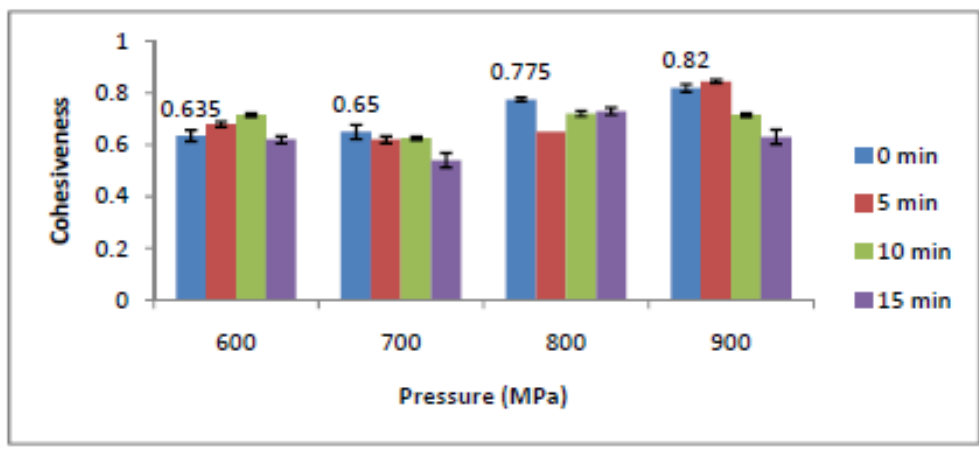

(c)

Figure 5. Effect of High pressure processing and treatment time on cohesiveness of various egg components: (a) EW, (b) EY, and (c) WLE

From quality point of view, HPP gives fresh and uncooked flavor in the egg gels. All egg components behave differently from each other on pressurizing due to variation in composition as egg white is rich in proteins (ovalbumin, ovotransferrin, and ovomucid); whereas egg yolk on other hand is a rich source of fat (unsaturated and saturated fatty acids). Generally, hardness is correlated to the rupture strength of the sample; springiness represents rubberiness, and cohesiveness is the degree of difficulty to break down a sample (Sanderson, 1990).

\section{Conclusions}

The effect of high pressure treatments on some physico-chemical properties on EY, EW and WLE were studied. Textural properties of all egg components were significantly affected by high pressure treatments. These processing treatments changed significantly with change in pressure level. By increasing pressure, egg components changed from liquid state to complete gel with coagulation and gelation of egg components. Egg gels were formed at high pressure level greater than $600 \mathrm{MPa}$ at temperature well below that required for thermal gel formation. HPP lead to formation of full set egg gels with improved physicochemical characteristics and without any cooked flavors. Further investigation is required on microbiological aspects and functional properties of post-processed samples before implementing this study to industrial sector. 


\section{Acknowledgements}

The authors wish to acknowledge financial support from the Natural Sciences and Engineering Research Council (NSERC) of Canada Discovery Grant (DG) Program. Parts of this manuscript was presented as a poster at the Institute of Food Technologists Annual Meeting in Chicago, IL in 2010 (Singh \& Ramaswamy, 2010). Travel grant was given by the Agricultural Research Institute of Canada (AIC) and poster is available on AIC website.

\section{References}

Ajaypal, S., \& Ramaswamy, H. S. (2010). Effect of high-pressure treatment on physicochemical properties of egg components. Presented at the 2010 Annual meeting of Institute of Food Technologists, Chicago, IL. Retrieved from http://www.aic.ca/about/pdf/Foundation/Ajaypal_Singh.pdf

Azarpazhooh, E., \& Ramaswamy, H. S. (2011). Optimization of Microwave-Osmotic Pretreatment of Apples with Subsequent Air-Drying for Preparing High-Quality Dried Product. International Journal of Microwave Science and Technology, 12. http://dx.doi.org/10.1155/2011/687548

Basak, S., \& Ramaswamy, H. (1998). Effect of high pressure processing on the texture of selected fruits and $\begin{array}{lllll}\text { vegetables. } \quad \text { Journal } & \text { Texture }\end{array}$ http://dx.doi.org/10.1111/j.1745-4603.1998.tb00185.x

Bourne, M. C. (1982). Food texture and viscosity: concept and measurement. New York, USA: Academic Press.

Bridgeman, P. (1914). The coagulation of albumen by pressure. Journal of Biological Chemistry, 19(4), 511-512.

Carlez, A., Veciana-Nogues, T., \& Cheftel, J. C. (1995). Changes in colour and myoglobin of minced beef meat due to high pressure processing. Lebensmittel-Wissenschaft und-Technologie, 28(5), 528-538. http://dx.doi.org/10.1006/fstl.1995.0088

Chen, A. H., Larkin, J. W., Clark, C. J., \& Irwin, W. E. (1979). Textural analysis of cheese. Journal of Dairy Science, 62(6), 901-907. http://dx.doi.org/10.3168/jds.S0022-0302(79)83346-9

Friedman, H. H., Whitney, J. E., \& Szczesniak, A. S., (1963). The texturometer-a new instrument for objective texture measurement. Journal of Food Science, 28(4), 390-396. http://dx.doi.org/10.1111/j.1365-2621.1963.tb00216.x

Hayashi, R., Kawamura, Y., Nakasa, T., \& Okinaka, O. (1989). Application of high pressure to food processing: pressurization of egg white and yolk, and properties of gels formed. Agricultural and Biological Chemistry, 53(11), 2935-2939. http://dx.doi.org/10.1271/bbb1961.53.2935

Hermansson, A. (1982). Gel characteristics-Structure as related to texture and water binding of blood plasma gels. Journal of Food Science, 47(6), 1965-1972. http://dx.doi.org/10.1111/j.1365-2621.1982.tb12923.x

Johnson, T. M., \& Zabik, M. E. (1981). Gelation properties of albumin proteins, singly and in combination. Poultry Science, 60(9), 2071-2083. http://dx.doi.org/10.3382/ps.0602071

Juliano, P., C., \& Bilbao, S. (2012). Shelf-Stable Egg-Based Products Processed by High Pressure Thermal Sterilization. Food Engineering Reviews, 4(1), 55-67. http://dx.doi.org/10.1007/s12393-011-9046-4

MacDougall, D. B. (2002). Colour in food: improving quality. Woodhead Publishing Limited, Cambridge, England. http://dx.doi.org/10.1533/9781855736672

Messens, W., Estepar-Garcia, J., Dewettinck, K., \& Huyghebaert, A. (1999). Proteolysis of high-pressure-treated $\begin{array}{lllll}\text { Gouda cheese. } & \text { International Dairy } & \text { Journal, } & 9(11), & 782 .\end{array}$ http://dx.doi.org/10.1016/S0958-6946(99)00152-1

Messens, W., Van Camp, J., \& Huyghebaert, A. (1997). The use of high pressure to modify the functionality of food proteins. Trends in Food Science \& Technology, 8(4), $107-112$. http://dx.doi.org/10.1016/S0924-2244(97)01015-7

Mine, Y. (1997). Effect of dry heat and mild alkaline treatment on functional properties of egg white proteins. Journal of Agricultural and Food Chemistry, 45(8), 2924-2928. http://dx.doi.org/10.1021/jf970158b

Ngarize, S., Adams, A., \& Howell, N. (2005). A comparative study of heat and high pressure induced gels of whey and egg albumen proteins and their binary mixtures. Food Hydrocolloids, 19(6), 984-996. http://dx.doi.org/10.1016/j.foodhyd.2004.12.008 
Oey, I., Lille, M., Van Loey, A., \& Hendrickx, M. (2008). Effect of high-pressure processing on colour, texture and flavour of fruit-and vegetable-based food products: a review. Trends in Food Science \& Technology, 19(6), 320-328. http://dx.doi.org/10.1016/j.tifs.2008.04.001

Okamoto, M., Kawamura, Y., \& Hayashi, R. (1990). Application of high pressure to food processing: textural comparison of pressure-and heat-induced gels of food proteins. Agricultural and Biological Chemistry, 54(1), 183-189. http://dx.doi.org/10.1271/bbb1961.54.183

Paraskevopoulou, A., \& Kiosseoglou, V. (1997). Texture Profile Analysis of Heat-Formed Gels and Cakes Prepared with Low Cholesterol Egg Yolk Concentrates. Journal of Food Science, 62(1), 208-211. http://dx.doi.org/10.1111/j.1365-2621.1997.tb04401.x

Pérez-Mateos, M., \& Montero, P. (1997). High pressure induced gel of sardine (Sardina pilchardus) washed mince as affected by pressure time temperature. Journal of Food Science, 62(6), 1183-1188. http://dx.doi.org/10.1111/j.1365-2621.1997.tb12240.x

Powrie, W. D., \& Nakai S. (1986). The Chemistry of Eggs and Egg Products (Chapter 6, pp. 97-139). Egg Science and Technology, AVI Publishing Company, Inc.

Rajan, S., Pandrangi, S., Balasubramaniam, V. M., \& Yousef, A. E. (2006). Inactivation of Bacillus stearothermophilus spores in egg patties by pressure-assisted thermal processing. LWT - Food Science and Technology, 39(8), 844-851. http://dx.doi.org/10.1016/j.lwt.2005.06.008

Sanderson, G. R. (1990). In G. P. H. Gellan (Ed.), Food Gels, Elsevier Applied Science (pp. 201-232). London. http://dx.doi.org/10.1007/978-94-009-0755-3_6

Szczesniak, A. S. (1963). Classification of Textural Characteristics. Journal of Food Science, 28(4), 385-389. http://dx.doi.org/10.1111/j.1365-2621.1963.tb00215.x

Tabilo-Munizaga, G., \& Barbosa-Cánovas, G. V. (2004). Color and textural parameters of pressurized and heat-treated surimi gels as affected by potato starch and egg white. Food Research International, 37(8), 767-775. http://dx.doi.org/10.1016/j.foodres.2004.04.001

Tunick, M. H., Mackey, K. L., Smith, P. W., \& Holsinger, V. H. (1991). Effects of composition and storage on the texture of mozzarella cheesE. Netherlands Milk and Dairy Journal, 45(2), 117-125.

Verlent, I., Van Loey, A., Smout, C., Duvetter, T., \& Hendrickx, M. (2004). Purified tomato polygalacturonase activity during thermal and high-pressure treatment. Biotechnology and Bioengineering, 86(1), 63-71. http://dx.doi.org/10.1002/bit.10920

Zhu, S., Ramaswamy, H., \& Simpson, B. (2004). Effect of high-pressure versus conventional thawing on color, drip loss and texture of Atlantic salmon frozen by different methods. Lebensmittel-Wissenschaft und-Technologie, 37(3), 291-299. http://dx.doi.org/10.1002/bit.10920

\section{Copyrights}

Copyright for this article is retained by the author(s), with first publication rights granted to the journal.

This is an open-access article distributed under the terms and conditions of the Creative Commons Attribution license (http://creativecommons.org/licenses/by/3.0/). 